DOI: 10.2478/linpo-2014-0012

\title{
An acoustic analysis of Pahari oral vowels
}

\author{
Abdul Qadir Khan \\ Department of English, University of Azad Jammu and Kashmir, \\ Muzaffarabad,Pakistan, aqkhan8873@yahoo.com
}

\begin{abstract}
Abdul Qadir Khan. An acoustic analysis of Pahari oral vowels. The Poznan Society for the Advancement of the Arts and Sciences. PL ISSN 0079-4740, ISBN 978-83-7654-388-8, pp. 29-39

The aim of the current study is to present an acoustic account of the twelve oral vowels of Pahari by analyzing their formant pattern (F1 and F2) and duration. To achieve this aim, an experiment was conducted. Tem native speakers of Pahari participated in the study and were given a list of 12 oral vowels in $\mathrm{CVC}$ context for recording, where $\mathrm{V}$ is the target vowel. The recorded material was analyzed by using Praat software. The spectral analysis (F1 and F2) show that Pahari has four close, six mid and two open vowels. The results also show that in term of duration these vowels occur in the form of long-short pairs that differ significantly quantatively (vowel duration). The study further exhibits that the short vowels are centralized as compared to their long counterpart.
\end{abstract}

Keywords: Formant Pattern (F1, F2), long-short pairs, duration, acoustic space

\section{Introduction}

According to the 16th edition of Ethnologue of World languages, there are seventyseven languages spoken in Pakistan. Out of these, seventy-two are indigenous languages (Lewis 2009). Pahari is an Indo-Aryan Language, spoken over a large area starting from Nepal and running through the foothills of the Himalayas, in the Himachal Pardesh, Indian administered part of Kashmir, Azad Jammu \& Kashmir and in the Northern Pakistan. The focus of present study is Pahari spoken in Azad Jammu and Kashmir, Pakistan. According to the 1998 census, Pahari is spoken by 3.5 million people living in the Pakistani administered part of Kashmir and a projected rate showed in 2004 that the speakers of Pahari are around 3.8 million. Lothers \& Lothers (2010) report that there are over one million Pahari speakers living in District Rawalpindi and District Abbottabad. Lothers \& Lothers (2003) state that there are over half a million immigrants in United Kingdom (UK) from this language group, mostly from district Mirpur. These reports show that estimated population of Pahari speakers today, is around five million.

In the small amount of literature previously written about Pahari, only a short description on vowels is found. Karnai (2003) has given nineteen oral and nasal vowels but did 
not use IPA symbols for the vowels; rather he uses Urdu characters. Khan (2012) presents the descriptive study of Pahari vowels based on minimal pairs and distribution of sounds in words. He established that Pahari has twelve oral vowels. So the present study is based on the descriptive study of Pahari Vowels (Khan 2012) and aims to present the vowel inventory of Pahari language after an acoustic analysis of Pahari vowels.

\section{Background}

\subsection{Vowel formant characteristics}

In articulatory phonetics, vowels are mainly described in terms of three features: (1) height of the tongue (2) backness of the tongue and (3) lip rounding. Acoustic studies approach the description of vowel differently. "An acoustic analysis of vowel stresses the different formant configurations that are characteristic of each vowel. The relationship among the vowels can be examined by comparing their formant values" (Olive et al. 1993). Vowels are frequently described with reference to their formant structure, which provides an indication of vocal tract resonance and therefore articulatory shape (Fant 1960). The high-low and front-back distinctions are represented by the first and second formants on the spectrogram (Olive et al. 1993). First formant (henceforth F1) shows the high-low distinction. That is, the lower the formant value, the higher the vowel. Second formant (henceforth F2) shows the front-back distinction. If the value of F2 is high, the vowel is closer to the front position. The relationships between (F1) and the height of tongue, and F2 and the front/back dimension ensures that when the first two formants of a set of vowel targets are plotted on axes with appropriate scaling characteristics, the result closely resembles the traditional auditory vowel map. Such vowel spaces, with axes F1 and F2, rely on the concept of the vowel target. The target is the vowel component least influenced by its surrounding phonetic context, and it is considered to be either a point in the time course of the vowel or else a section of time during which the vowel position remains stable. A single point is often used to provide a representation of the target position and for most vowels, this can be assumed to be approximately mid way though the nucleus.

\subsection{Vowel duration}

Cochrane (1970) states that vowels may be distinguished in terms of duration for those languages and dialects that employ phonemic vowel length. This durational contrast may or may not be the only distinctive feature between two vowels. For example, English short vowels $/ \mathrm{I} /, / \mathrm{\partial} /$ and $/ \mho /$ are qualitatively distinct from their corresponding long vowels. According to Tsukada (2002), vowel duration is used contrastively in some languages, but not in others. He states that English and Hindi differ from Japanese and Thai since both these languages use vowel duration as an acoustic cue for the length distinction in addition to qualitative differences to maintain the contrast between /I/ and /i:/, /u/ and /u:/, /a/ and /a:/. It shows that in Japanese and Thai, length contrast is a prominent cue, whereas English uses other acoustic cues, such as spectral differences. Watson \& Harrington (1999) claim that vowel classification experiments show increased accuracy when frequency and durational 
information are combined. According to Cochrane (1970), the major difference between long and short vowels is simply one of total vowel duration. However, the difference is relative rather than absolute as contextual and prosodic factors affect the ultimate length of the vowel. Peterson \& Lehiste (1960) describe short vowels as showing a short target and slow relaxation, whereas for long vowels, the target is maintained for longer followed by a more rapid offglide. Lindblom (1967) documents that openness is positively correlated with length, and therefore open vowels tend to be longer than close vowels. He suggests that this is universally the result of the increased biomechanical effort required to produce low vowels.

The study selected above mentioned two acoustic parameters namely Spectral and temporal characteristics to for the experiment with the aim to come up with the vowel inventory of Pahari oral vowels in the form of a quadrilateral by drawing F1XF2 plot.

\section{Methods}

\subsection{Participants}

Ten native speakers of Pahari, five male and five female participated in this study. They were students at the University of Azad Jammu and Kashmir, Muzaffarabad, born and raised in Pahari speaking area in Azad Jammu and Kashmir. They all speak Pahari with their friends, family and at market places. They speak Urdu with people who do not speak Pahari. Their ages range from 20 to 30 years at the time these recordings were made. All the participants were interacted with to ensure that they had no hearing or articulation problems. None of the speakers had reported any speech or hearing impairment.

\subsection{Stimuli}

A list of monosyllabic words exemplifying 12 monophthongs of Pahari was constructed such that the target vowels occur between $/ \mathrm{m} /$ and $/ 1 /$.

Table 1: List of words in CVC context used in this study

\begin{tabular}{cccc}
\hline Vowel & Words $/ \mathrm{mVl} /$ & Vowel & Words $/ \mathrm{mVl} /$ \\
\hline i: & mi:l & I & mil \\
e: & me:l & e & mel \\
$æ:$ & mæ:1 & $æ$ & mæl \\
a: & ma:1 & ə & məl \\
o: & mo:1 & o & mo:1 \\
u: & mu:1 & u & mul \\
\hline
\end{tabular}

\subsection{Recording}

Recording was done in five sessions in a quiet room at the University of Azad Jammu \& Kashmir, Muzaffarabad. The participant was seated comfortably in front of the laptop 
screen, wearing a headset microphone. The microphone was about two inches away from the left side of the participant's lips. The words with target vowels were displayed on laptop screen in random order. The participants were asked to read each word three times in random order. The participants were instructed to read words with normal speed. Ten speakers gave a total of 360 tokens (10 speakers $\times 3$ repetitions $\times 12$ vowels). They were recorded directly on Praat (www.praat.org) software by using high fidelity microphone.

\subsection{Measurement}

The waveforms and spectrograms, for each target vowel, were used to determine first two formant frequencies. Measures of the lowest two formants of vowels were made using Praat software. The words were segmented on the basis of visual information in a wide band spectrogram. F1 and F2 were determined and measured in $\mathrm{Hz}$ in the middle of the target vowel since it can be assumed that the influence of an adjacent segment is minimal and the articulatory target is maximally achieved in this position. The target is the vowel component least influenced by its surrounding phonetic context and is considered to be either a point in the time course of the vowel or else a section of time during which the vowel position remains stable. A single point is used to provide a representation of the target position and for most vowels; this is assumed to be approximately mid way through the nucleus. Figure 1 shows the spectrogram of a speaker's utterance 'mal' with the target vowel [a] selected in three cursors. The mid cursor indicates the middle of the formants at which measurement of the formant frequencies are taken in $\operatorname{Hertz}(\mathrm{Hz})$, while the two extreme cursors measure the duration of the vowel from the beginning of the sound (left) to the end (right) in seconds.

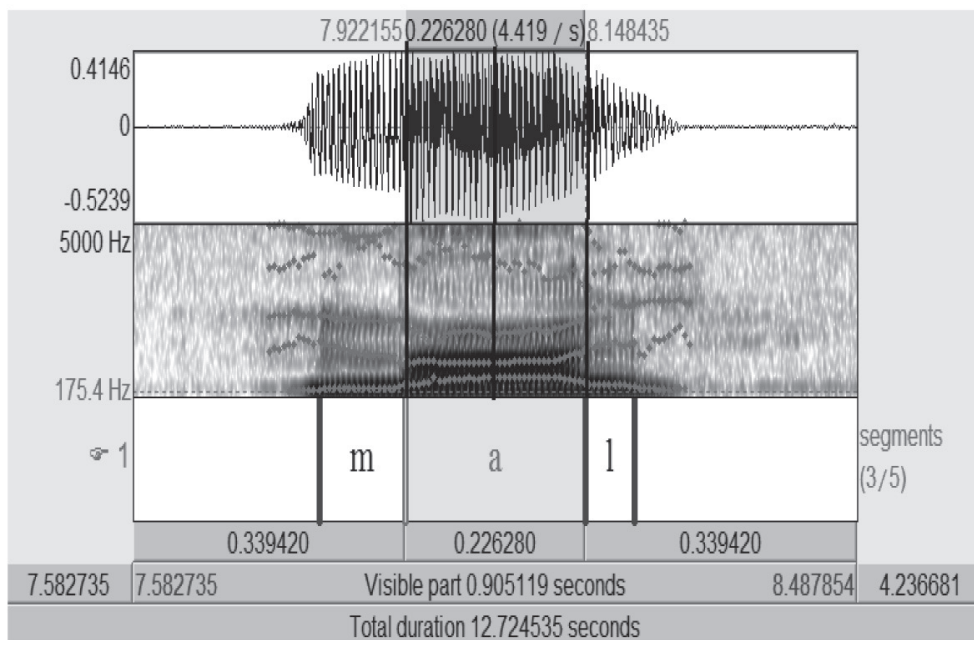

Figure 1: Spectrogram showing measurement of Formants and duration 


\section{Results and discussion}

As mentioned earlier, the parameters selected for acoustic analysis are the formant frequencies (F1, F2) and vowel duration. Table 2 illustrates mean F1 and F2 and Table 3 shows mean vowel duration values with standard deviations for the data from ten Pahari speakers in CVC context. The standard deviation represents the variance of means of the three tokens for each of the ten speakers. The measurements of three tokens within each participant are treated as repeated measures and therefore averaged.

\subsection{Formant frequencies}

Table 2 gives the mean F1 and F2 values with standard deviations. Figures 2 and 3 display the mean F1 and F2 frequencies in $\mathrm{Hz}$ of the vowels, respectively.

Table 2: Pahari CVC mean vowel formants in Hertz with standard deviations

\begin{tabular}{lcr}
\hline Vowels & F1 (s.d) & \multicolumn{1}{c}{ F2 (s.d) } \\
\hline i: & $310(28.5)$ & $2234(170.5)$ \\
I & $332(34.6)$ & $2140(170.1)$ \\
e: & $412(29.6)$ & $1909(131.5)$ \\
e & $401(29.8)$ & $1850(99.1)$ \\
$æ:$ & $578(51.1)$ & $1730(106.9)$ \\
$æ$ & $567(44.6)$ & $1660(83.1)$ \\
a: & $625(78.9)$ & $1143(95.8)$ \\
ə & $582(76.7)$ & $1158(92.2)$ \\
o: & $460(52.5)$ & $955(123.6)$ \\
o & $441(48.2)$ & $984(142.7)$ \\
u: & $364(61.7)$ & $854(159.8)$ \\
u & $370(37.5)$ & $950(135.6)$ \\
\hline
\end{tabular}

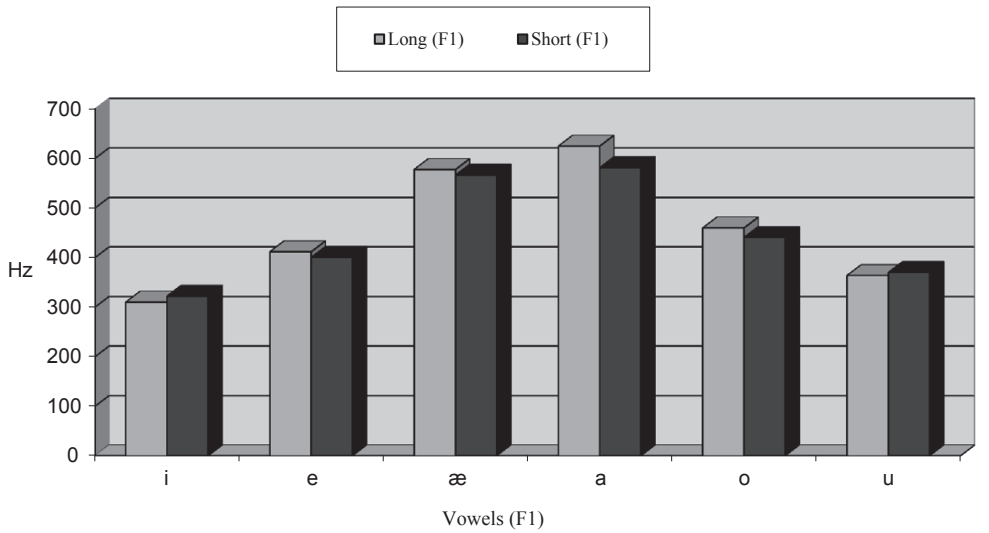

Figure 2: F1 of long and short vowels 
The bar diagram above shows that there is very little difference between the F1 values of short and long vowels.

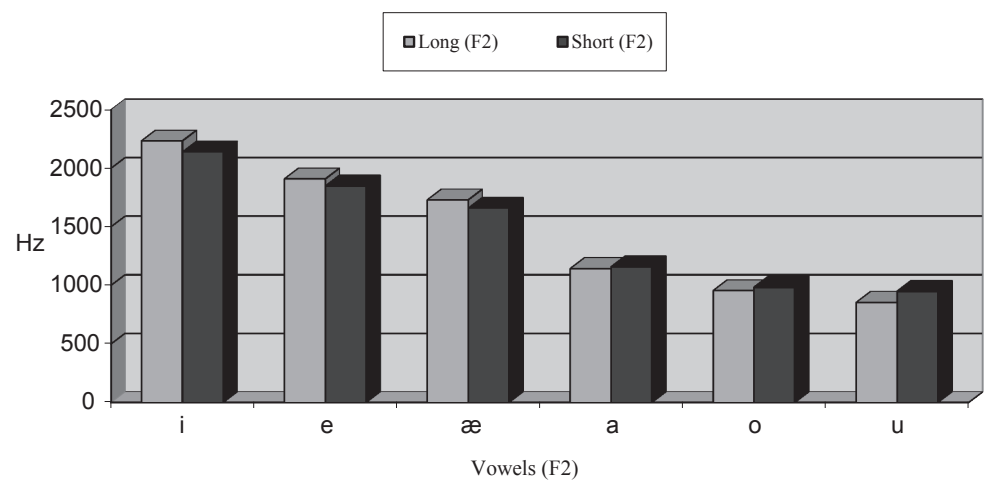

Figure 3: F2 of long and short vowels

Figure 3 shows that there is very little difference in F2 values of long vowels and their corresponding short vowels. Figure 4 illustrates F1-F2 difference more elaborately.

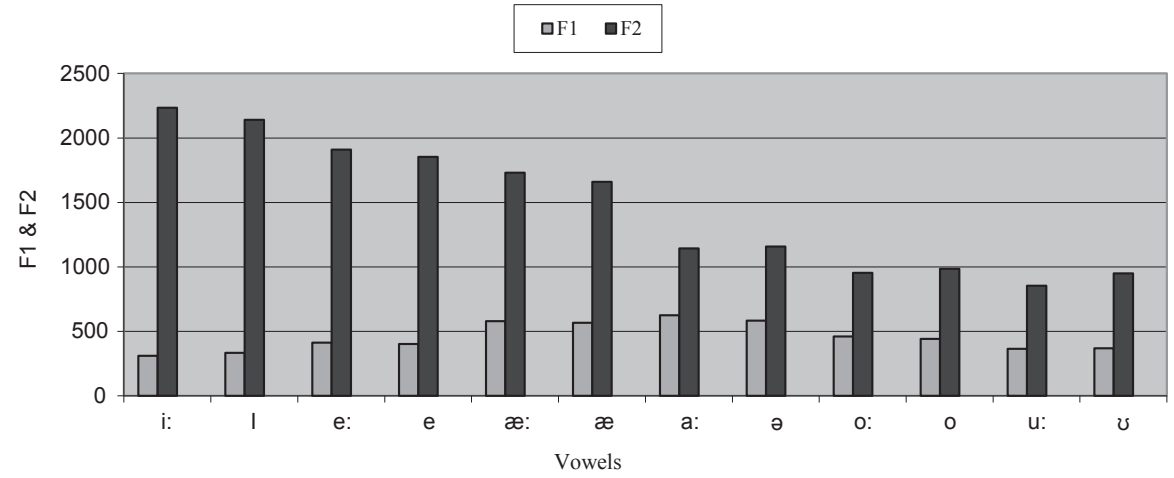

Figure 4: F1-F2 contrast between long and short vowels

Figure 4 show that, for front vowels, F1 becomes lower when the constriction in the oral cavity increases. As /i:/ is the most constricted front vowel, it has the lowest F1. It means that F1 increases as the tongue position gets lower for front vowels i.e., F1 of high front vowel /i:/ is $310 \mathrm{~Hz}$, while F1 of mid front vowel /æ:/ is $567 \mathrm{~Hz}$. In case of back vowels, F1 decreases with the height of the tongue i.e., mid back long vowel /o:/ has $460 \mathrm{~Hz}$, while high back long vowel /u:/ has $370 \mathrm{~Hz}$. In contrast to F1, /i:/ has the highest F2 and /u:/ has the lowest F2. This suggests that high vowels have low F1 and low vowels have high F1. Pahari has only one low vowel /a:/ and it has the highest F1 value $(625 \mathrm{~Hz})$. Figure 4 further displays that the maximum separation between F1 and F2 occurs with the close front vowels, and it is the smallest with the low vowels. For back vowels, F2 is much lower and closer to F1. 


\subsection{Vowel duration}

The means for the duration values are provided in Table 3, while Figure 5 illustrates the relative nucleus durations for each vowel. It is observed that when speakers of the same geographical region produce same vowel, the result is different vowel durations. This is because some speakers speak faster and some speak slower.

Table 3: The means of duration values and standard deviations for the vowels in ms

\begin{tabular}{lrc}
\hline & Mean duration & Standard deviation \\
\hline i: & 218 & 19.3 \\
I & 93 & 15.5 \\
e: & 225 & 18.2 \\
e & 92 & 07.2 \\
æ: & 228 & 25.8 \\
$æ$ & 99 & 10.5 \\
a: & 235 & 18.8 \\
ə & 94 & 12.8 \\
o: & 221 & 41.6 \\
o & 88 & 11.2 \\
u: & 218 & 17.5 \\
U & 96 & 15.1 \\
\hline
\end{tabular}

Long-Short Vowel Contrast

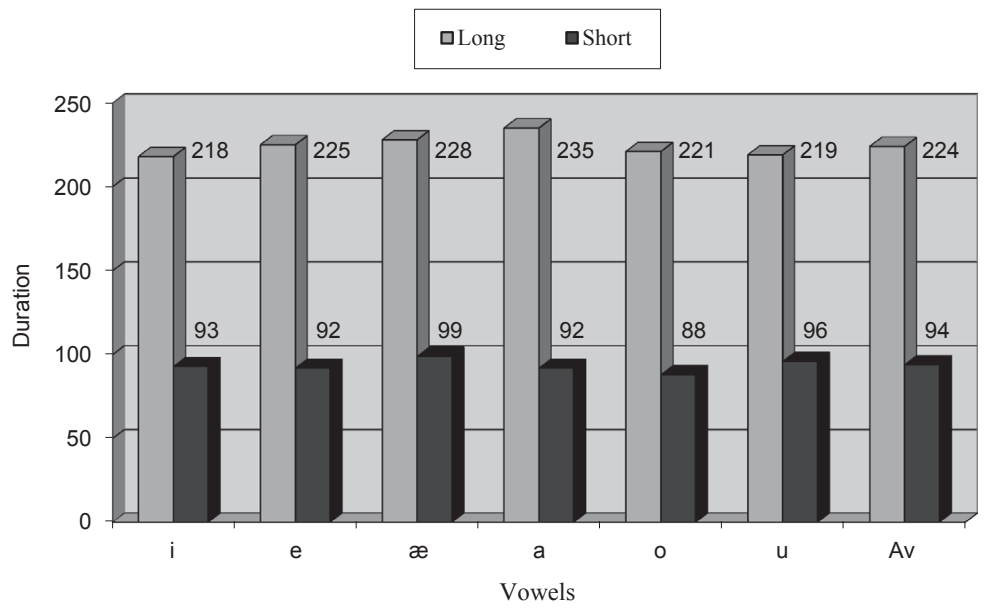

Figure 5: The length of vowels in milliseconds

The bar chart above shows the average duration of each long and short vowel in the speech of selected participants. The data indicate that durational contrast between long and short vowels is very much prominent and distinctive. The average duration of long and short vowels is $224 \mathrm{~ms}$ and $94 \mathrm{~ms}$, respectively. The data further show the increase in length with vowel openness. /a:/ has $235 \mathrm{~ms}$ duration that is longer than that of two other front mid and front close vowels /e:/ and /i:/ respectively. The length of back vowels decreases with vowel 
closeness as the close back vowel /u:/, is shorter than mid back vowel /o:/. It is also evident that all the long vowels are over two times longer than their corresponding short vowels.

The above results show that durational contrast is significant. It is phonemic in Pahari. Though it is the most distinctive and prominent and does help the listener to place vowels in large categories, such as long and short, still it is not sufficient in itself to enable identification of any individual vowel. For example, [e] and [I] can't be differentiated on the basis of duration as both are short and have mean duration 93 and $92 \mathrm{~ms}$, respectively. It means only quantity is not enough to identify the individual vowels. To identify individual vowels both the quality, quantity and quality cues are important in Pahari.

\subsection{Vowel space}

This section shows the vowel plots that were generated with Plot Formants. The graph shows F2 on the horizontal axis and F1 on the vertical axis.

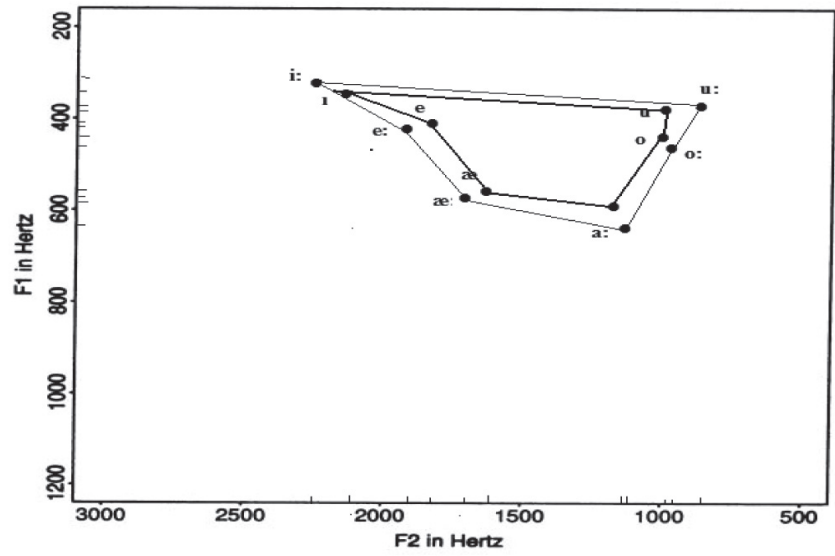

Figure 6: F1-F2 acoustic space for Pahari vowels

Figure 6 shows the acoustic space enclosed by long and short vowels. As it is seen, all the short vowels are centralized and do form the inner circle of vowel space as compared to their corresponding long vowels, which are distributed peripherally in vowel space. This shows that the acoustic space enclosed by long vowels is more than that for the short vowels.

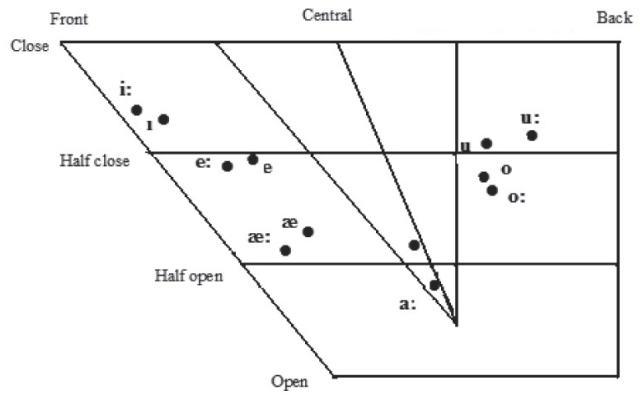

Figure 7: Quadrilateral of Pahari vowels 
Figure 7 shows that only 2 vowels, one long and one short are central, while other 10 are peripheral in Pahari. The long and short vowels are located close to each other in the quadrilateral. This shows that there is very little spectral/qualitative difference between long and short vowels. This suggests that duration is an important and distinctive cue in Pahari. It further exhibits that all the short vowels are centralized as compared to their long counterparts. Another trend appears that F1 of mid short vowels is lower than that of their corresponding long vowels. In contrast, all the close centralized vowels have higher F1 than that of their long counterparts. The following table summarizes the description of Pahari Oral vowels.

Table 4: Summary of Pahari oral vowels description

\begin{tabular}{lllll}
\hline $\mathrm{i}:$ & front & close & long & unrounded \\
$\mathrm{I}$ & front & close & short & unrounded \\
$\mathrm{e}:$ & front & mid & long & unrounded \\
$\mathrm{e}$ & front & mid & short & unrounded \\
æ: & front & mid & long & unrounded \\
æ & front & mid & short & unrounded \\
$\mathrm{a}:$ & central & mid & long & unrounded \\
ə & central & mid & short & unrounded \\
o: & back & mid & long & rounded \\
o & back & mid & short & rounded \\
u: & back & close & long & rounded \\
v & back & close & short & rounded \\
\hline
\end{tabular}

Based on the acoustic analysis, it is concluded that Pahari operates on 12 vowel system. These vowels are presented in Table 5.

Table 5: Oral vowel phonemes

\begin{tabular}{lccc}
\hline & Front & Central & Back \\
Close & i: , I & & ひ, u: \\
Mid & e: , e & & o, o: \\
& æ: , & ə & \\
Open & & a: & \\
\hline
\end{tabular}

\section{Conclusion}

With respect to Pahari oral vowels, the analysis shows that Pahari has four close, six mid, two open vowels. The data suggest that oral vowels are described as occurring in the form of long-short pairs that differ significantly quantitatively (vowel duration) and qualitatively (spectral characteristics). This study shows that long vowels are over two times longer (e.g., /i:/ and /I/ are $218 \mathrm{~ms}$ and $93 \mathrm{~ms}$, respectively) in terms of duration than their short- counterparts. Spectral differences also occur among long-short pairs i.e., all the short front vowels show low F2, while all the short back vowels show higher F2 than that of their corresponding long vowels. This shows that long vowels are peripheral in quadrilateral, 
while short vowels are centralized as compared to their corresponding long vowels. Long vowels enclose more vowel space than short vowels. Duration cue is the most important as the language clearly exhibits long-short distinction and duration is phonemic in Pahari vowel system.

\section{References}

Baart, Joan. 1999. Acoustic phonetics. Dallas: Summer Institute of Linguistics.

Cochrane, G. R. 1970. Some vowel durations in Australian English. Phonetica 22. 240-250.

Cox, Felicity. 1999. Vowel change in Australian English. Phonetica 56. 1-27.

Clark, John \& Yallop, Collin. 1992. An introduction to phonetics and phonology. Oxford: Blackwell.

Clements, George N. 1980. Vowel harmony in nonlinear generative phonology: an autosegmental model. Bloomington: Indiana University Linguistics Club.

Davenport, Mike \& Hannahs, Stephen J. 2005. Introducing Phonetics and Phonology. London: Hodder Arnold.

Disner, S. F. 1984. Insights on vowel spacing. In Maddieson I., Patterns of sounds, 136-155. Cambridge: Cambridge University Press.

Erickson, Molly. 2000. Simultaneous effects on vowel duration in American English: A covariance structure modelling approach. Journal of the Acoustical Society of America 108. 2980-2995.

Fant, Gunnar. 1960. Acoustic theory of speech production. The Hague: Mouton.

Jha, Sunil K. 1985. Acoustic analysis of the Maithili diphthongs. Journal of Phonetics 13. 107-115.

Jones, Glyn. 1984. The distinctive vowels and consonants of Welsh. In Ball \& Jones (eds.), 40-64.

Karnai, Mian Karim Ullah. 2007. Pahari aor Urdu: ik Taqabali Jaiza. Islamabad: National Language Authority.

Kenstowicz, Michael. 1970. On the notation of vowel length in Lithuanian. Papers in Linguistics 3. 73-113.

Kent, Raymond \& Charles, Read. 2002. The acoustic analysis of speech. San Diego: Singular Publishing Group.

Khan, Abdul Qadir. 2012. Phonology of Pahari: A Study of Segmental and Suprasegmental Features of Poonch Dialect. University of Azad Jammu \& Kashmir, Muzaffarabad. (Unpublished doctoral dissertation)

Khan, Abdul Qadir \& Sarwar, Naveed \& Bukhari, Nadeem Haider. 2011. Syllable Onset Clusters and Phonotactics in Pahari. www.languageinindia.com/march2011/quadirkhanpaharifinal.

Klatt, Dennis. 1976. Linguistic uses of segmental duration in English: acoustic and perceptual evidence. Journal of the Acoustical Society of America 59. 1208-1221.

Ladefoged, Peter. 1996. Elements of acoustic phonetics. Chicago: University of Chicago Press.

Ladefoged, Peter. 2001. A course in phonetics. USA: Harcourt College Publishers.

Ladefoged, Peter \& Maddieson Ian. 1996. Sounds of the world's languages. Oxford: Blackwell.

Lewis, Paul. 2009. Ethnologue: Languages of the World, Sixteenth edition. Dallas, Tex.: SIL International. Online version: www.ethnologue.com.

Liljencrants, John \& Lindblom, Bjorn. 1972. Numerical simulation of vowel quality systems: the role of perceptual contrast. Language 48. 839-862.

Lindblom, Bjorn. 1967. Vowel duration and a model of lip-mandible coordination. Speech Transmission Laboratories Progress Status Report 4. 1-29.

Lindblom, Bjorn. 1975. Experiments in sound structure. Paper presented at Eighth International Congress of Phonetic Sciences, Leeds.

Lothers, Michael \& Lothers, Laura. 2010. Pahari and Pothwari: A sociolinguistics survey. Islamabad: Summer Institute of Linguistics.

Lothers, Michael \& Lothers, Laura. 2003. Mirpuri immigrants in England: A sociolinguistic survey. SIL International.

Maddieson, Ian. 1984. Patterns of sounds. Cambridge: Cambridge University Press.

Masica Collin. 1991. The Indo-Aryan languages. Cambridge: Cambridge University Press.

Olive, Joseph \& Greenwood, Alice \& Coleman, John.1993. Acoustic of American English speech. New York: Springer-Verlag.

Peterson, Gordon \& Lehiste, Ilse. 1960. Duration of syllable nuclei in English. Journal of the Acoustical Society of America 3. 693-703. 
Pickett, James M. 1999. The Acoustic of speech communication fundamentals, speech perception theory, and technology. Boston: Allan and Bacon.

Stevens, Kenneth \& Blumstein, Sheila. 1975. Quantal aspects of consonant production and perception: a study of retroflex stop consonants. Journal of Phonetics 3. 215-233.

Tsukada, Kimiko. 2002. An acoustic comparison between American English and Australian English vowels. 7th International Conference on Spoken Language Processing (ICSLP 2002), Denver, Colorado, USA, 2257 2260.

Watson, Cathrine \& Harrington, Jonathan. 1999. Acoustic evidence for dynamic formant trajectories in Australian English vowels. Journal of the Acoustical Society of America 106. 458-468. 